\title{
Case Analysis of Seismic Reinforcement of Historical Buildings----Based on Reinforced Concrete Frame Structure
}

\author{
Fan Tingting, Hong Yan, Liu Weidong
}

School of Environment and Architecture, University of Shanghai for Science and Technology, Shanghai, China

\section{Email address:}

2298109503@qq.com (Fan Tingting),yan7983@hotmail.com (Hong Yan),wdliu2010@126.com (Liu Weidong)

\section{To cite this article:}

Fan Tingting, Hong Yan, Liu Weidong. Case Analysis of Seismic Reinforcement of Historical Buildings----Based on Reinforced Concrete Frame Structure. Science Discovery. Vol. 5, No. 5, 2017, pp. 390-398. doi: 10.11648/j.sd.20170505.25

Received: July 24, 2017; Accepted: August 21, 2017; Published: September 18, 2017

\begin{abstract}
China has a long history and has survived many excellent historical buildings, These historic buildings have inadequate capacity or do not meet the requirements of earthquake resistance and need to be reinforced. This paper briefly describes the seismic reinforcement method of concrete reinforced concrete structures at first, and then made a contrastive analysis on the historical buildings before and after the reinforcement. Finally, made a comment on the contradiction between the method of aseismatic reinforcement and the protection principle of historic buildings.
\end{abstract}

Keywords: Historical Buildings, Reinforced Concrete Structure, Seismic Strengthening, Protection Principle

\section{历史建筑抗震加固的案例分析--以钢筋混凝土框架结构为主}

范婷婷，洪燕，刘卫东

环境与建筑学院, 上海理工大学, 上海, 中国

邮箱

2298109503@qq.com（范婷婷）,yan7983@hotmail.com（洪燕）, wdliu2010@126.com（刘卫东）

摘要: 中国历史悠久, 从古至今, 留存下来了很多优秀的历史建筑, 这些历史建筑都存在承载力不足或者不满足抗震 设防要求需要对其进行加固。本文首先对传统的钢筋混凝土结构的抗震加固方法进行简单的概述, 然后结合钢筋混凝 土框架结构历史建筑的加固案例进行了加固前后的对比分析, 最后就抗震加固方法与历史建筑的保护原则之间存在的 矛盾问题发表了自己的看法。

关键词: 历史建筑, 钢筋混凝土结构, 抗震加固, 保护原则

\section{1. 引言}

中国是一个历史悠久的文明古国, 从古至今, 中国在 不断发展中, 留存下来了很多历史建筑。这些不断演变过 来的各式各样的历史建筑都有着丰富的历史意义, 同时也 反映了各个时代的特征。从民国时期, 中国开始出现大量 的钢筋混凝土框架结构建筑, 此种结构具有使用空间大, 建筑平面布置比较灵活, 并且采用混凝土这种材料相比于 木结构, 耐久性、防火性能等方面都占有很大的优势。
尽管钢筋混凝土框架结构建筑出现的时间相对比较晚, 但是早期出现的一些建筑超过了相关规范上所规定的正常 使用年限范围, 尤其是一些没有满足现有抗震规范上规定的 抗震等级的建筑, 对于此类钢筋混凝土框架历史建筑需要进 行相应的加固设计, 才能使得建筑物满足正常使用状态。另 外, 对历史建筑进行相应的加固设计同样也是为了使其恢复 原先模糊的历史意义, 使得这些独具特色的历史建筑留存下 来, 恢复它原本的面貌, 为了更好地保留它的历史价值。 
如何采取恰当的加固方法, 怎样在遵循历史建筑“修 旧如旧”的修缮原则的前提条件下, 采用合适的加固方式, 保证建筑本身的正常使用性质以及它们的安全性, 是目前 值得进一步研究与探讨的话题。

本文主要对传统的钢筋混凝土框架结构历史建筑的 抗震加固方法作相应的归纳总结, 在此基础上, 对采用框 架结构历史建筑的案例进行加固前后效果上的比较分析, 并且针对保持历史建筑的原真性与加固方法上存在的矛 盾进行探讨, 并提出相应的建议。

\section{2. 相关理论}

\section{1. 历史建筑保护原则}

历史建筑在进行修缮与加固的时候, 应区别于一般的建 筑, 在考虑到建筑结构加固后的安全性以及适用性的同时, 还需要遵守历史建筑保护的相关原则, 建立在这些保护原则 的基础上, 对历史建筑进行加固。根据《雅典宪章》与《威 尼斯宪章》关于历史建筑保护应该遵循的原则如表1所示。

表1 历史建筑的保护原则。

\begin{tabular}{ll}
\hline 原则 & 特点 \\
\hline 整体性原则 & 保护历史建筑的同时, 不仅仅只是对历史建筑本身考虑, 应该与周围的整体环境结合起来, 使得历史建筑恢复到原本的整体性面貌[1]。 \\
真实性原则 & 保留建筑原有的建造手法、结构方式、建筑材料等历史遗下留下来的东西, 保历史的痕迹[2]。 \\
可逆性原则 & 在对历史建筑加固时, 应该考虑到未来会发现对结构更好的加固方法, 采取的方法最好是可拆卸的, 保证未来的新加固技术 \\
必要性原则 & 可以对结构进行再次的修缮[3]。 \\
可识别原则 & 对加固过程中建筑平时的维护和保养, 减少对其加固修缮的次数[3]。 \\
可持续性原则 & 在历史建筑加固与修缮时, 充分考虑到以绿色的建筑材料, 有效利用可再生节能材料。 \\
\hline
\end{tabular}

（表格来源：作者自绘）

\section{2. 混凝土框架结构抗震加固方法概述}

为了提高混凝土框架结构构件的抗震承载力, 使得结 构变形能力增强以及改变框架结构体系等目的, 需要对这 些混凝土框架结构进行抗震加固, 根据实际情况的不同选 择相应合适的加固方案[4]。

目前, 中国抗震加固规范《混凝土结构加固技术规范 GB50367-2013》规定的钢筋混凝土框架结构建筑的抗震加
固方法主要包括了以下几类[5]: 增大截面加固法、置换混 凝土加固法、体外预应力加固法、外包型钢加固法、粘贴 钢板加固法、粘贴纤维复合材加固法、预应力碳纤维复合 板加固法、增设支点加固法、预张紧钢丝绳网片-聚合物 砂浆面层加固法、绕丝加固法、植筋技术、裂缝修补技术。 关于混凝土框架结构常用加固方法、自身特点及限制条件 [5]如表2、表3所示。

表2 混凝土框架结构常用加固方法。

\begin{tabular}{|c|c|c|}
\hline 加固方法 & 直用的加固构件 & 具体加固措施 \\
\hline 增大截面加固法 & 筋混凝土受压以及受弯构件 & 采用同种材料来加大原结构构件的截面[6]。 \\
\hline 置换混凝土加固法 & $\begin{array}{l}\text { 有严重局部缺陷或者受压区混凝土强度明显偏 } \\
\text { 低导致的承载力不足的承重构件, 如柱和梁。 } \\
\text { 连续滐和秝简支浾 }\end{array}$ & $\begin{array}{l}\text { 采用钢管、钢板、钢筋以及千斤顶组成的传力体系, 再现浇混凝土以 } \\
\text { 置换原有强度等级低的混凝土。 }\end{array}$ \\
\hline 体外预应力加固法 [8] & & 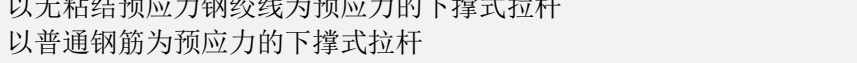 \\
\hline & & \\
\hline 外包型钢加固法 & $\begin{array}{l}\text { 抗震能力以及截面承载能力不足的钢筋混凝 } \\
\text { 土柱和梁 }\end{array}$ & $\begin{array}{l}\text { 怉型钢加固法 } \\
\text { 加固法 }\end{array}$ \\
\hline 粘贴钢板加固法 & 钢筋混凝土的受拉构件, 大偏心受压以及受弯 & 用胶粘剂将钢板贴在构件外部的一种加固方法。 \\
\hline $\begin{array}{l}\text { 粘贴纤维复合材加固 } \\
\text { 法 }\end{array}$ & $\begin{array}{l}\text { 钢筋混凝土结构轴心受压、大偏心受压、受拉 } \\
\text { 以及受弯构件 }\end{array}$ & \multirow{7}{*}{ 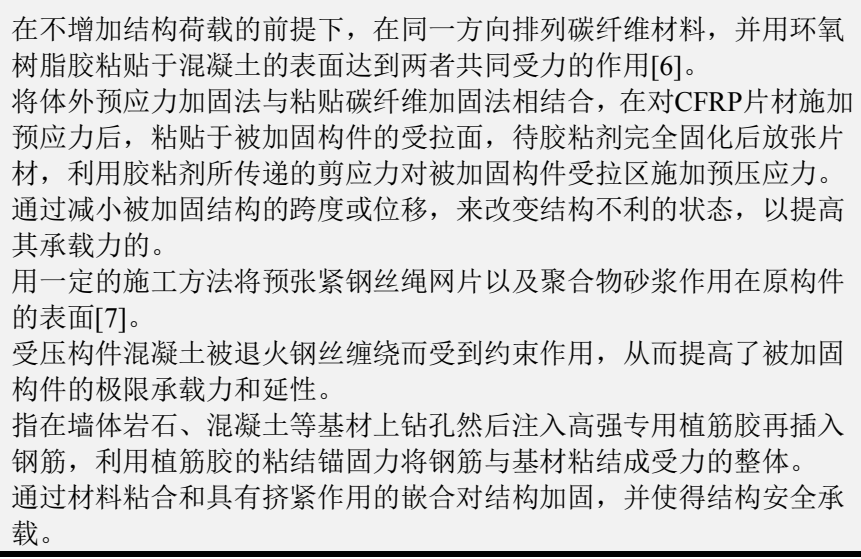 } \\
\hline $\begin{array}{l}\text { 预应力碳纤维复合板 } \\
\text { 加固法 }\end{array}$ & $\begin{array}{l}\text { 配筋不足或者截面偏小的钢筋混凝土受拉、受 } \\
\text { 弯以大偏心受压构件 }\end{array}$ & \\
\hline 增设支点加固法 & 梁、板、桁架 & \\
\hline $\begin{array}{l}\text { 预张紧钢丝绳网片-聚 } \\
\text { 合物砂浆面层加固法 }\end{array}$ & 钢筋混凝土柱、梁、墙 & \\
\hline 绕丝加固法 & 需要提高位移延性的钢筋混凝土柱 & \\
\hline 植筋技术 & $\begin{array}{l}\text { 适用于以结构胶种植带肋钢筋和全螺纹螺杆 } \\
\text { 后的钢筋混凝土结构构件的针固设计 }\end{array}$ & \\
\hline 针栓技术 & 普通混凝土承重结构 & \\
\hline
\end{tabular}

（表格来源：作者自绘） 
表3 混凝土框架结构常用加固方法的自身特点及限制条件。

\begin{tabular}{|c|c|c|}
\hline 加固方法 & 自身特点 & 限制条件 \\
\hline 增大截面加固 & $\begin{array}{l}\text { 1. 有效提高结构承载力; } \\
\text { 2. 不影响建筑本身的净空高度。 }\end{array}$ & $\begin{array}{l}\text { 1. 改变了原有构件的截面尺寸, 影响原有建筑结构的外观。 } \\
\text { 2. 施工过程中的湿作业持续时间久。 }\end{array}$ \\
\hline 置换混凝土 & 1. 不影响建筑本身的净空高度。 & 1. 施工的湿作业时间久。 \\
\hline & 1. 提高结构与构件的承载能力; & 1. 不适用于素混凝土的构件, 以及纵向受力钢筋一侧配筋率 \\
\hline 体外预应力加固 & $\begin{array}{l}\text { 2. 减小结构以及构件正常使用过程中的变形或裂缝宽 } \\
\text { 度。 }\end{array}$ & $\begin{array}{l}\text { 小于 } 0.2 \% \text { 的构件; } \\
\text { 2. 用该方法加固后不能长期处于高于 } 60^{\circ} \mathrm{C} \text { 的环境中。 }\end{array}$ \\
\hline 外包型钢加固 & $\begin{array}{l}\text { 1. 避免了施工中湿作业时间持续久的缺点; } \\
\text { 2. 保持了不改变原始截面尺寸小的状态。 } \\
\text { 3. 现场工作量较少、受力可靠。 }\end{array}$ & $\begin{array}{l}\text { 1. 用钢量相对较大; } \\
\text { 2. 在没有防护情况下, 不能长期处于高于 } 60^{\circ} \mathrm{C} \text { 的环境中。 }\end{array}$ \\
\hline 粘贴钢板加固 & $\begin{array}{l}\text { 1. 施工快速、现场无湿作业或仅有抹灰等少量湿作业, } \\
\text { 对生产和生活影响小; } \\
\text { 2. 加固后对原结构外观和原有净空无显著影响。 } \\
\text { 1. 轻质高强, 一般无需搭接, 能适应曲面形状混凝土 }\end{array}$ & $\begin{array}{l}\text { 1. 采用此项加固技术, 需要做好防火以及加固后的结构应处 } \\
\text { 于 } 60^{\circ} \mathrm{C} \text { 以下的环境中; } \\
\text { 2. 处于特殊环境中应对其采取防护措施。 } \\
\text { 1. 采用此项加固技术, 需要做好防火以及加固后的结构应处 }\end{array}$ \\
\hline 粘贴纤维复合材加固 & $\begin{array}{l}\text { 的粘贴要求; } \\
\text { 2. 耐腐蚀、耐潮湿、施工便捷。 } \\
\text { 1. 有效提高结构的承载能力; }\end{array}$ & $\begin{array}{l}\text { 于 } 60^{\circ} \mathrm{C} \text { 以下的环境中; } \\
\text { 2. 处于特殊环境中应对其采取防护措 } \\
\text { 1. 不适用于素混凝土的构件, 以及纵向受力钢筋一侧配筋率 }\end{array}$ \\
\hline 预应力碳纤维复合板 & $\begin{array}{l}\text { 2. 可变被动加固为主动加固。可以使CFRP (碳纤维增 } \\
\text { 强复合材料) 高强特性得到提前发挥, 从而有效减小甚 } \\
\text { 至消除CFRP片材应变滞后的现象, 达到更好的加固效 } \\
\text { 果。 }\end{array}$ & $\begin{array}{l}\text { 小于 } 0.2 \% \text { 的构件; } \\
\text { 2. 采用此项加固技术, 需要做好防火以及加固后的结构应处 } \\
\text { 于 } 60^{\circ} \mathrm{C} \text { 以下的环境中; } \\
\text { 3. 在特殊环境中需要采取防护措施。 }\end{array}$ \\
\hline 增设支点加固 & 1. 受力明确、简便可靠, 且易拆卸、复原。 & $\begin{array}{l}\text { 1. 显著影响使用空间。 } \\
\text { 2. 不耐高温, 不耐湿，需要采取防锈、隔热的措施。 }\end{array}$ \\
\hline $\begin{array}{l}\text { 预张紧钢丝绳网片-聚 } \\
\text { 合物砂浆面层加固 }\end{array}$ & $\begin{array}{l}\text { 1. 能使用在高湿、高温的环境中; } \\
\text { 2. 大大提高被加固构件的开裂刚度; } \\
\text { 3. 对被加固构件表面的平整度的要求不是特别高 }\end{array}$ & $\begin{array}{l}\text { 1. 采用此项加固技术, 需要做好防火以及加固后的结构应处 } \\
\text { 于 } 60^{\circ} \mathrm{C} \text { 以下的环境中; } \\
\text { 2. 处于特殊环境中应对其采取防护措施。 }\end{array}$ \\
\hline 绕丝加固法 & 提高构件的承载力 & $\begin{array}{l}\text { 施工过程复杂。 } \\
\text { 1. 在钻孔施工过程中, 容易偷工减料, 影响加固效果 }\end{array}$ \\
\hline 植筋技术 & $\begin{array}{l}\text { 1. 施工简便, 固着力大, 可缩短工期, 可快速承载; } \\
\text { 2. 粘结材料耐老化、抗腐蚀。 }\end{array}$ & $\begin{array}{l}\text { 2. 对针固部位的原构件混凝土要求较高, 不得有局部缺陷; } \\
\text { 3. 采用此项加固技术, 需要做好防火以及加固后的结构应处 } \\
\text { 于 } 60^{\circ} \mathrm{C} \text { 以下的环境中; 处于特殊环境中应对其采取防护措施。 }\end{array}$ \\
\hline 针栓技术 & 1. 施工简便，不需要临时支撑。 & $\begin{array}{l}\text { 1. 该方法不能适用于严重风化的普通混凝土结构或者轻质混 } \\
\text { 凝土结构。 }\end{array}$ \\
\hline
\end{tabular}

（表格来源：作者自绘）

除了《混凝土结构加固技术规范GB50367-2013》规定 的一些常用的加固方法, 《建筑抗震加固技术规程 给出了另外的方法, 包括增设抗震墙或翼墙、钢筋混凝土 套加固、增设支撑加固以及填充墙加固方法[4]。

JGJ116-2009》对于多层及高层混凝土房屋的加固方法,

表4 钢筋混凝土框架结构历史建筑加固案例。

\begin{tabular}{|c|c|c|c|c|}
\hline 编号 & 加固案例 & 建筑功能 & 建造时间 & 加固时间 \\
\hline (1) & 北京火车站 & & 1959年 & 1999年 \\
\hline (2) & 济南火车站 & 历史纪念建筑 & 1908年 & 1993年 \\
\hline (3) & 中国国家博物馆 & & 1959年 & 2006年 \\
\hline (4) & 中国人民革命军事博物馆 & & 1958年 & 2012年 \\
\hline (5) & 中国国家图书馆 & & 1929年 & 1997年 \\
\hline (6) & 南京博物院 & 文化教育建筑 & 1937年 & 2007年 \\
\hline (7) & 东南大学老图书馆 & & 1923年 & 2009年 \\
\hline (8) & 北京展览馆 & & 1953年 & 2002年 \\
\hline (9) & 北京京西宾馆 & & 1964年 & 2001年 \\
\hline (10) & 上海外滩源中实大楼 & & 1929年 & 2007年 \\
\hline (11) & 上海华东医院南楼文物建筑 & & 1926年 & 1996年 \\
\hline (12) & 上海扬子饭店 & 办公服务建筑 & 1931年 & 2008年 \\
\hline$(13)$ & 上海东海大楼 & & 1931年 & 2007年 \\
\hline (14) & 上海大来大楼 & & 1921年 & 2011年 \\
\hline (15) & 沈阳市政府大楼 & & 1935年 & 1997年 \\
\hline (16) & 上海大世界 & & 1917年 & 2005年 \\
\hline (17) & 上海市百一店老楼 & 工商金融建筑 & 1936年 & 2008年 \\
\hline 18 & 上海外滩源兰心大楼 & & 1927年 & 2009年 \\
\hline
\end{tabular}

\footnotetext{
（表格来源：作者自绘）
} 


\section{3. 案例分析}

\section{1. 历史建筑抗震加固案例概要 [9]}

历史建筑对于一个国家的文化、历史都弥足珍贵，它 是不可再生的稀有资源, 反映着一个国家各个时代的建筑 特色以及文化价值。然而, 随着时代的变迁, 它们大多数
都处于“高龄”阶段, 这些建筑遭受着耐久性与适用性等的 考验。此外, 部分此类建筑物建造时抗震设防没有考虑或 者考虑不够完善。因此, 需要采取合适的方法进行加固。 目前, 关于钢筋混凝土框架结构历史建筑加固的案例如表 4, 各加固案例各部位所用的加固方法如表5。

表5 各加固案例采用的主要加固方法。

\begin{tabular}{|c|c|c|c|c|c|}
\hline 加固方法 加固部位 & 基础 & 柱 & 梁 & 楼板 & 整体结构 \\
\hline 树根桩加固技术 & (1)(2) & & & & \\
\hline 扩大基础面积 & (3) & & & & \\
\hline 水泥粉煤灰碎石桩（CFG桩） & (5) & & & & \\
\hline 双液快凝注浆法 & (11) & & & & \\
\hline 增大截面法 & & (2)(3) (6) (7)(10)(12) (13) (14) (16) (17)(18) & (2)(3) (7)(12)(14)(17) & (2) & \\
\hline 外包钢加固 & & (1)(3)(12) 16 & (2)(3)(13) 16 & & \\
\hline 碳纤维加固 & & (3)(9)(14)(16)(18) & (3)(10) 13 (18) & (10) 13 (17) & \\
\hline 混凝土围套 & & (5) & & & \\
\hline 植筋和化学螺栓 & & (13) & (13) & & \\
\hline 粘贴钢板加固 & & (9) & (13)(14)(16) (17) & (13) 16 & \\
\hline 消能减震加固 & & & & & (1)(3)(8)(9)(15)(16) \\
\hline 隔震加固 & & & & & (4) 6 \\
\hline
\end{tabular}

注: 表 5 中的数字编号表示表 4 中的案例的编号

（表格来源：作者自绘）

表 5 反映了钢筋混凝土框架结构历史建筑各部位常采 用的抗震加固方法, 因此, 钢筋混凝土框架结构历史建筑 基础部位常用的加固方法主要是树根桩加固技术, 对于历 史建筑的柱和梁的加固方法主要最多的是增大截面法、外 包钢加固法以及碳纤维加固法。

然而增大截面法这种加固方法是大多数框架结构历 史建筑采用的加固方法。增大截面加固法相比于其他的加 固方法拆卸困难, 基本上加固后的结构构件不能再通过拆 卸的方式回到原本的状态。而且柱和梁采用了加大截面法 以后, 改变了结构构件原有的尺寸大小。因此, 这些就引 发了上文中提到的关于历史建筑应该遵循的“原真性”以 及“可逆性”的保护原则的问题。

在抗震加固方法和历史建筑的保护原则之间如何解 决存在的矛盾是值得深入探讨的一个问题。针对这一问题, 在上述案例中选取对历史建筑空间变化影响比较大的上 海历史建筑中混凝土柱采用增大截面加固法的案例进行 较为详细的分析。

\section{2. 采用增大截面加固法的上海历史建筑案例概述}

\subsection{1. 上海扬子饭店}

位于上海市黄浦区汉口路 740 号云南中路路口的上海 扬子饭店是一幢层高为 8 层的钢筋混凝土框架结构的建筑 物, 始建时间是1931年, 由留法建筑设计师李幡设计, 整 个饭店建筑风格独特, 采用了葡萄牙式的建筑风格, 建筑 面积 $9500 \mathrm{~m}^{2}$ 。图1是扬子饭店加固前的整体结构平面图。 建造时间至今已经有一定的年代, 建筑物外观以及内在都
有一定程度的破损, 影响了房屋结构的正常使用状态。因 此, 大楼的业主于 2007 年对扬子饭店进行了大规模的装修 及改造, 建筑结构进行了抗震鉴定, 根据抗震鉴定检测结 果主要针对该历史建筑的柱、梁采取了合适的加固方法对 扬子饭店进行改造加固, 对柱采用了加大截面法、碳纤维 加固的方法。

结合上文提到的加大截面法的加固方法与历史建筑 保护原则中的“可逆性”与“原真性”存在矛盾, 现取案例中 柱采用的增大截面法进行分析。案例中, 对建筑物外观的 影响程度大小分别对不同空间部位的柱采用的增大截面 的部位是有区别的。对不影响大楼外观的柱采用了四面混 凝土围套加固, 即四个截面都增大面积。对影响建筑外观 的边柱采用三面围套加固以及单面围套加固, 对角柱采用 了双面围套加固。增大截面法加固后的平面简图如图2。

\subsection{2. 上海外滩源兰心大楼}

上海外滩源兰心大楼位于上海市黄浦区圆明园路 185 号, 建造于1927年, 由通和洋行设计, 原结构是一栋地上 层高为7层（屋面南侧另设有两层塔楼）的钢筋混凝土框 架结构建筑, 总建筑面积达 $2005 \mathrm{~m}^{2}$ 。房屋的原结构平面简 图如图3所示。大楼于2009年进行改造加固, 分别对柱、 梁以及墙体进行了相应的加固。其中对房屋的西侧边柱采 用了增大截面加固法, 解决了原结构中框架柱截面尺寸不 足, 轴压比过大, 纵向钢筋配筋不足等结构安全性问题。 加固后的柱墙平面简图, 建筑外观图如图4, 图5所示。建 筑的使用功能由改造前的兰心戏院变为集商业零售、办公 室、餐饮为一体的商业化建筑。 


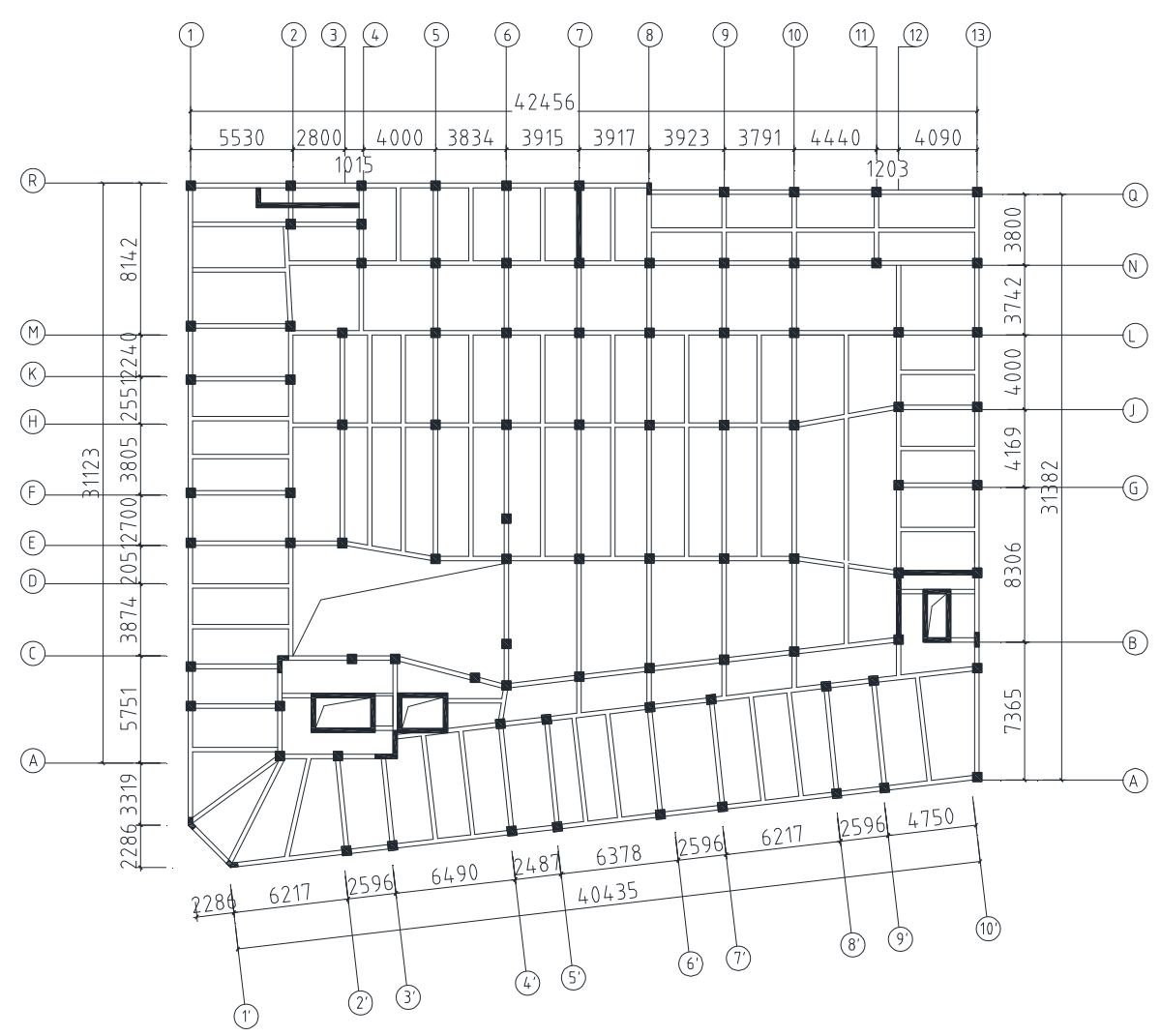

（图片来源：作者自绘）

图1 扬子饭店原结构平面图

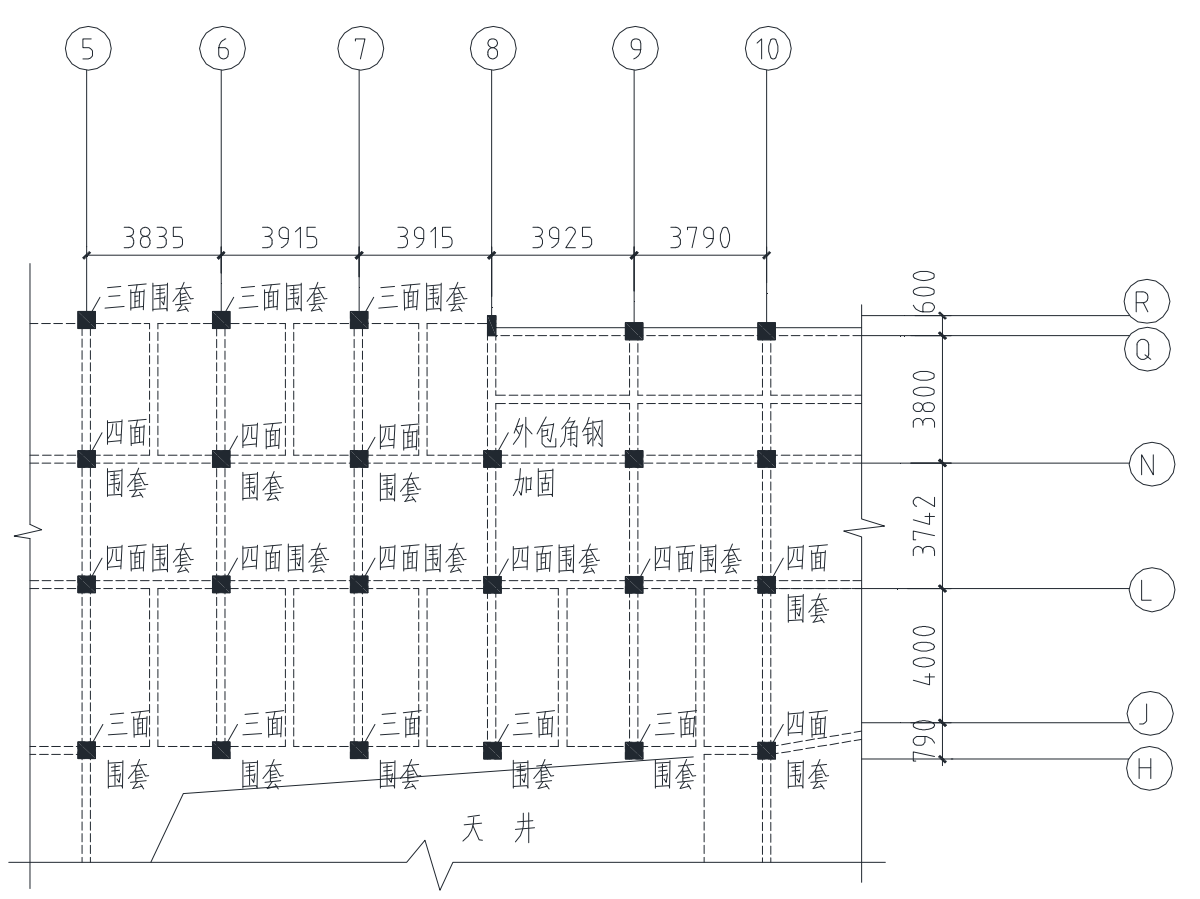

（图片来源：作者自绘）

图2 扬子饭店局部柱加固平面简图 


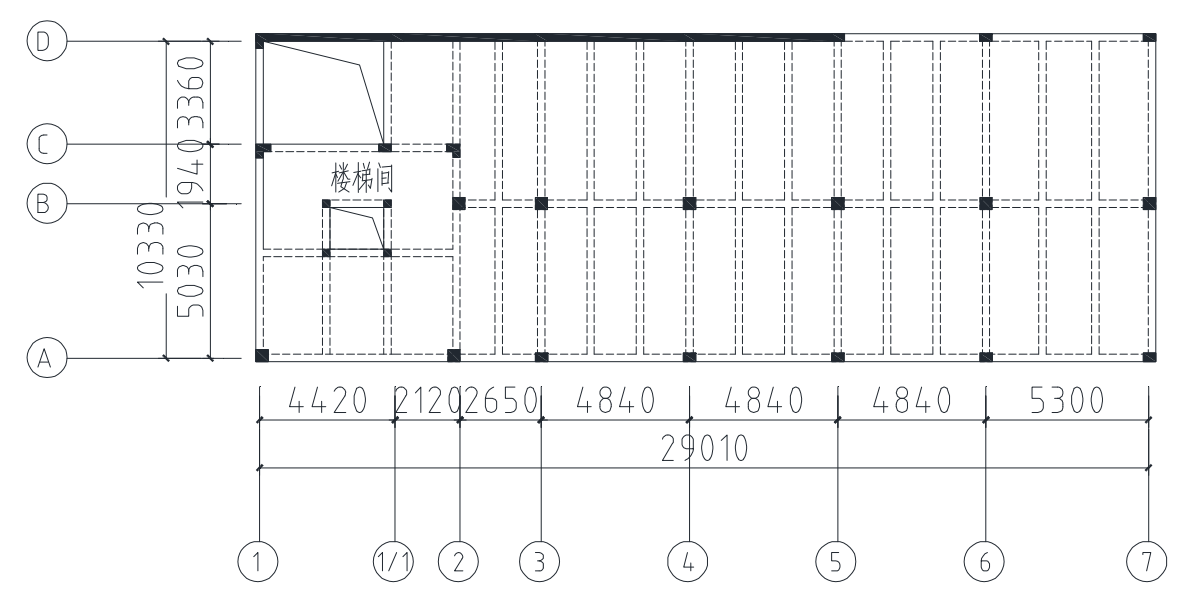

（图片来源：作者自绘）

图3 兰心大楼原结构平面简图

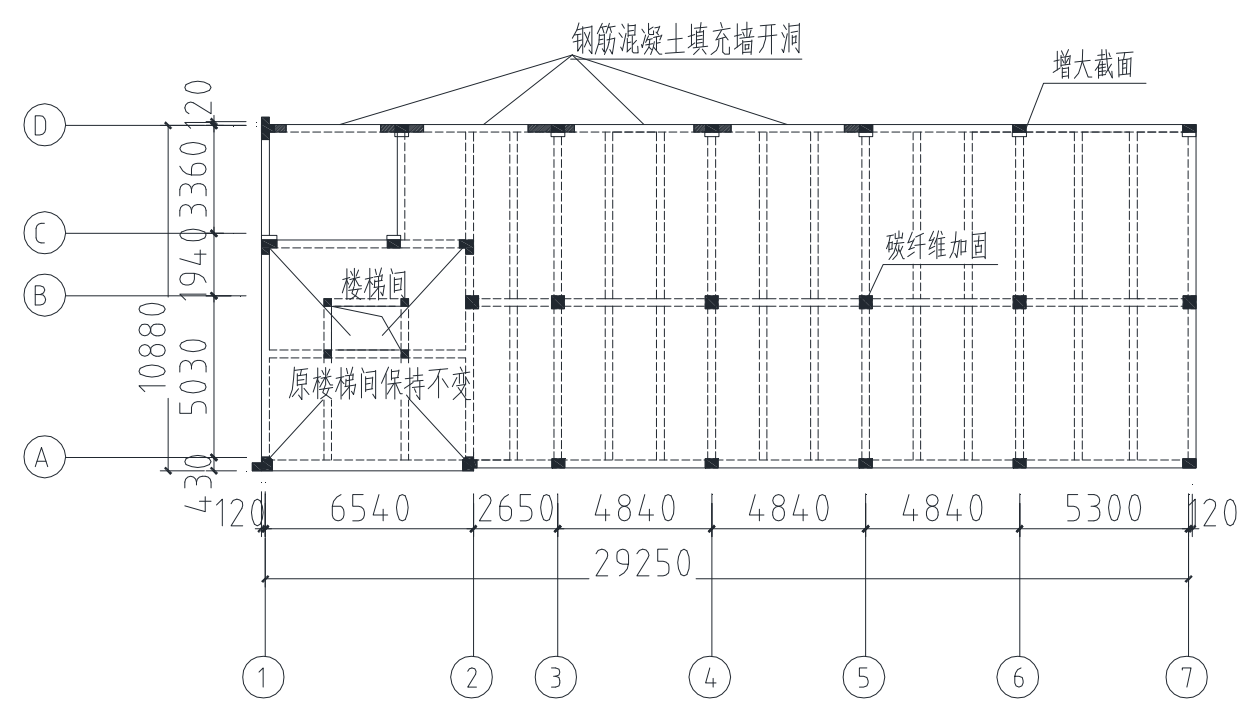

（图片来源：作者自绘）

图4 兰心大楼柱墙加固后平面简图

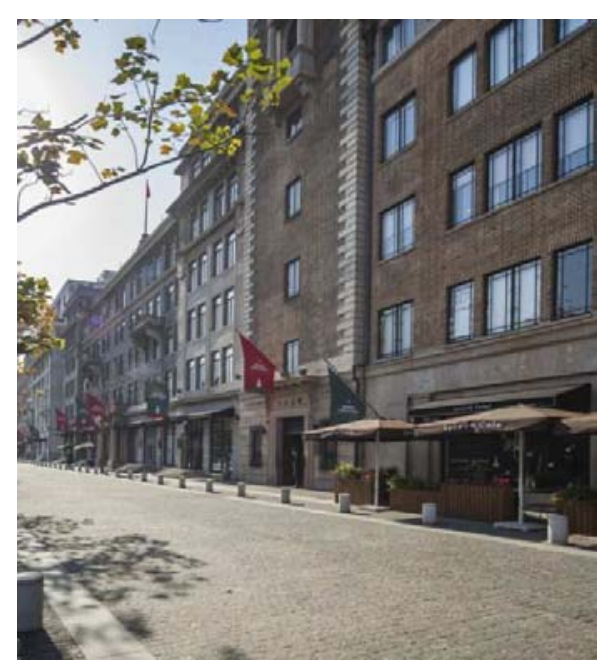

(图片来源: 洛克外滩源网站http://www.rockbund.com/cn/) 图5 加固后的建筑外观图。

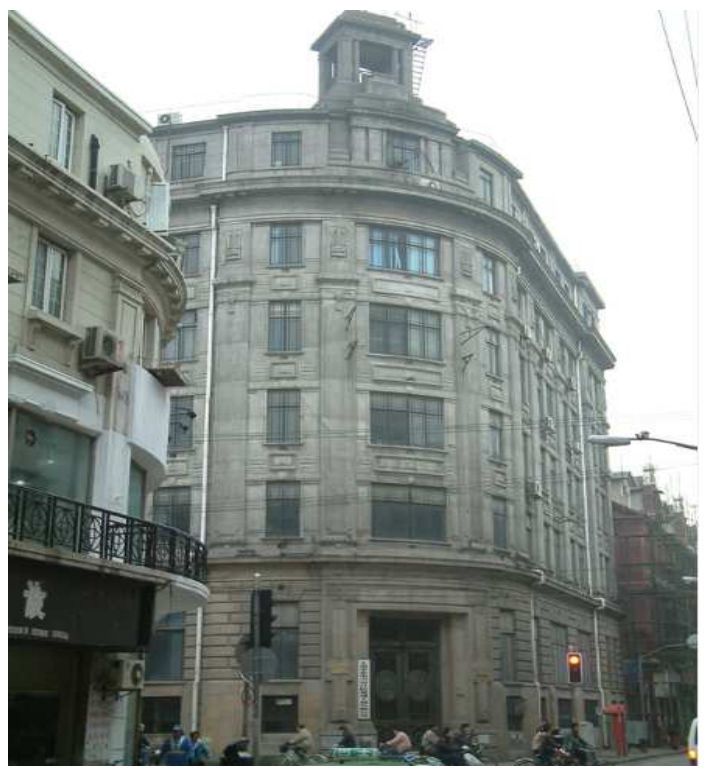

图6 加固前的建筑外观图。 
(图片来源：MSN中文网首页外滩源174街坊历史建筑修缮：中国实业 银行大楼http://msnphoto.eastday.com/2011gqhd/20130601_4/index.html）

\section{2.3. 上海外滩源中实大楼}

上海外滩源中实大楼位于外滩历史文化风貌区, 始建 于1929年, 由通和洋行设计, 该建筑属于当时比较早的钢 筋混凝土框架结构建筑。建筑面积为 $7903 \mathrm{~m}^{2}$, 房屋地上 6 层, 局部为7层, 地下 1 层。该建筑原来的功能是银行办公 大楼，该建筑于2007年改造加固完成，改造后为集商业、 办公楼、餐厅为一体的商业化建筑。针对建筑结构的特点, 对不同的构件采取了适合的加固方式。加固过程中，对柱 也是采用了增大截面法的加固方式，采用此加固方法后， 有效地保证了加固后柱的耐久性能, 大幅度提升了构件的 承载力和延性, 加固效果明显。加固前后建筑外观图如图 6 , 图7所示。

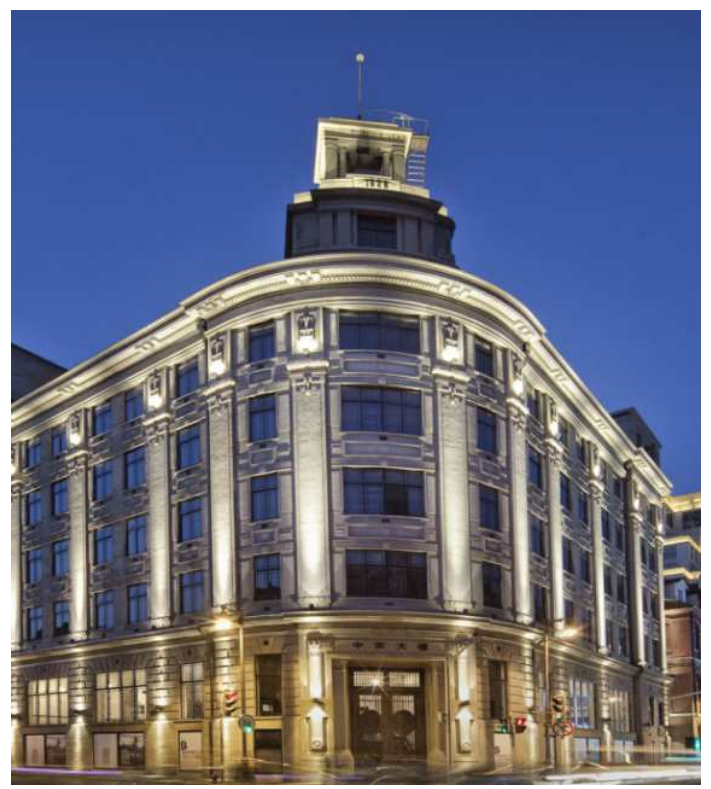

(图片来源：洛克外滩源网站http://www.rockbund.com/cn/) 图7 加固后的建筑外观图。

\section{3. 案例的分析与评价}

在以上三个历史建筑的案例中, 对柱子的加固上都采 用了增大截面法, 加固方法上存在一定的相似性。针对历 史建筑保护原则与加固方法上的矛盾, 对上述三个案例从 加固目的、建筑结构加固前后的使用功能转换以及历史建 筑加固的意义这三个方面进行评价与分析。

\section{3. 1. 历史建筑加固的目的与保护原则的关系}

上海扬子饭店、外滩源兰心大楼以及中实大楼这三个 案例加固的主要目的都是为了提高建筑结构的承载力、提 高房屋的抗震能力。采用加大截面加固法不仅可以有效地 提高框架柱的承载力, 而且结构的整体刚度也得到了提高。 因此, 在历史建筑的加固目的方面, 以上钢筋混凝土框架 结构历史建筑的加固都是建立在保护原则的基础上进行 的建筑的改造再利用, 而不是纯粹的以历史建筑的保护为 目的进行加固的。例如, 以上几个案例中, 在采用增大截
面的加固方法时, 保证了建筑结构暴露在建筑外部的柱子 形状不改变, 只是对处于结构内部空间的部分加大截面, 这样保证了原有建筑外观始终保持不变。虽然建筑的内部 空间结构有稍微的改变, 但是相对于整体结构结构体系、 建筑风格、建筑立面都没有发生改变, 因此, 从历史建筑 保护原则的“真实性”的角度看, 在建筑外观上满足了 “真 实性”所规定的保持建筑外观、结构方式不改变。虽然加 大截面法用于历史建筑的加固与历史建筑保护原则中规 定的“可逆性”这一原则相矛盾, 但是案例中, 对于钢筋混 凝土框架结构历史建筑更多的是加固后的使用功能, 而不 是加固后限制其使用功能。并且, 多数混凝土框架结构建 筑是在民国时期才开始慢慢出现的, 距离现在年代并不久 远, 其历史价值相对较小, 人们对此类建筑的改造再使用 价值一定程度上超过其历史价值。在截面增加不多的情况 下, 在保留建筑外观不变的前提下, 还是可以接受的。

\section{3. 2. 加固前后使用功能的转换}

上海扬子饭店在改造前后没有发生使用功能的转变, 始终作为饭店功能使用。通过改造再装修, 扬子饭店不仅 保留了历史建筑本身的历史价值, 也提升了使用功能, 饭 店以五星级精品酒店重新开业, 酒店围绕着浓厚的历史气 息, 建筑经济效益得到提升。

上海外滩源兰心大楼改造加固前是兰心戏院，改造加 固后变为集商业零售、办公室、餐饮为一体的商业化建筑。 兰心大楼经过加固后建筑功能转换明显, 建筑历史风貌得 到恢复, 使用功能得到了很大的改善。同时, 建筑结构承 载力、抗震能力得到有效提升。上海外滩源兰心大楼的加 固前后建筑功能发生了巨大的转变, 建筑的经济效益得到 明显的提升。因此, 证明该加固过程的目的更加注重的是 建筑的改造后再利用, 而不是以保护历史建筑为主要目的 去进行加固。

上海中实大楼也是由原来的银行办公大楼改造成了 集商业、办公楼、餐厅为一体的商业化建筑，建筑改造前 后功能发生了很大的改变。通过改造后功能的转换, 不管 是结构的承载力或者是建筑的使用价值方面都得到了很 大程度的提升。

\subsection{3. 加固的必要性分析}

由于一些历史建筑本身超过了原本规定的抗震使用 年限, 当时建造的建筑已经不满足现有抗震规范所规定的 条件, 因此, 历史建筑的抗震能力无法达到正常使用的要 求, 对其进行抗震加固是必要的, 对历史建筑进行抗震加 固后, 历史建筑的抗震能力达到要求。

\section{3. 4. 历史建筑加固前后的抗震分析}

结合上述三个上海历史建筑的抗震加固案例, 历史建 筑抗震加固前后的抗震分析如表 6 。

增大截面法可以有效的应用在历史建筑的抗震加固 上。从表 6 可以看出, 增大截面加固方法可以有效的改善 地震作用下楼层的层间位移角, 以及调整原来不满足规范 要求的结构柱的轴压比, 使得结构柱的轴压比得到适当的 降低。同时, 采用增大截面法能比较可靠的改善框架柱的 配筋以及截面尺寸。 


\section{3. 5. 钢筋混凝土框架结构历史建筑抗震加固的意义}

中国的钢筋混凝土框架结构历史建筑大多产生于民 国时期, 对其进行相应的改造加固并不会很大程度上影响
建筑本身。建筑空间的再利用目的大于历史保护意义, 因 此对空间局部变化的要求不是很严格。

表6 历史建筑抗震加固前后的对比分析。

\begin{tabular}{lll}
\hline 加固案例 & 加固前 & 加固后 \\
\hline 上海扬子饭店[9] & 1. 相应层间位移角大于规范限值; & 1 . 地震作用下的层间位移角小于规范限值 $1 / 550 ;$ \\
& 2. 多数框架柱的轴压比大于 0.9 , 不满足规范限值。 & 2 所有的框架柱的轴压比均保证低于 0.9 。 \\
& 1. 建筑底层、二层局部框架柱的轴压比大于 0.9 , 不满足 & 1 . 层间位移角满足规范要求; \\
上海外滩源兰心大楼[9] & 规范限值; & 2. 采用增大截面法的加固方法使得框架柱截面尺寸、 \\
& 2. 部分框架柱截面尺寸以及配筋不足; & 配筋满足要求; \\
& 3.Y向层间位移角大于规范限值。 & 3. 层间位移角满足要求。 \\
& 1. 大楼五层、六层局部柱的截面尺寸较小; & 1. 增大截面法可靠的大幅度的提高了柱的承载力; \\
上海外滩源中实大楼[9] & 2. 大楼底层和地下室的个别柱轴压比大于 0.9 。 & 2. 降低了轴压比, 满足规范要求。 \\
\hline
\end{tabular}

\section{4. 增大截面法在历史建筑抗震加固中的可行性分析}

近现代钢筋混凝土历史建筑其结构的整体性相对完 好, 因此, 成为抗震加固改造利用的主要对象。根据案例 分析结果, 现阶段的钢筋混凝土历史建筑的改造利用目的 大于其历史性价值, 因此对加固所带来的空间变化要求相 对自由。以上这三个案例都可以归结为历史建筑保护后的 再利用。即要求历史建筑结构外观大致不变, 内部使用功 能布局可以有一定的变动。因此, 对于近现代的钢筋混凝 土历史建筑, 主要目的在于历史建筑的保护后再利用, 在 不破坏建筑外观的前提下, 采用增大截面法进行加固的方 法也是可行的。

但是历史价值较高的此类建筑能否仍然沿用加大截 面法等加固方式, 有待探讨。比如, 对北京故宫的加固如 果采用了增大截面法, 这样一类加固方法或多或少会对历 史建筑本身产生建筑空间上的改变, 甚至本身的建筑材料 将会被新的材料覆盖, 改变了建筑本身面貌以后的建筑会 一定程度上降低它的历史价值, 那么也就失去了对历史建 筑改造加固本身的意义。所以, 本身历史价值高的历史建 筑不适合采用增大截面法这类加固方法。对于历史价值高 的建筑，应该注重建筑本身面貌，比如，表5中一些历史 建筑采用的消能减震加固、隔震加固法。这类加固方法相 比于增大截面法更加适用, 不仅有效的提高了抗震能力, 承载力, 而且可以维护历史建筑本身结构空间不变。这类 加固方法一定程度上解决了加固方法与历史建筑保护原 则两者相冲突这一问题。国外也有很多类似的例子, 比如, 新西兰的国会大厦, 美国的盐湖城大厦, 日本的国立西洋 美术馆等都采用了隔震型的加固方法 $[10]$ 。因此, 隔震技 术在历史建筑的加固中的应用是有待深入研究与发展的。

\section{4. 结论}

本文针对历史建筑的相关保护原则，同时对钢筋混凝 土结构的加固方法作了相应的概括。并列举了近些年对此 类历史建筑的加固案例, 通过对加固前后的案例的对比分 析, 总结了如下几点:

（1）目前，中国的历史建筑加固改造方面取得了很 多的成果, 在相应规范上规定的相关的抗震加固方法也日 益趋于完善。
（2）对历史建筑的加固方法应该建立在一般结构的 加固方法上, 以遵循历史建筑保护的原则为前提, 尤其在 采用加固方法的时候, 应同时考虑历史建筑保护原则所涉 及到的“真实性”与“可逆性”原则。

(3) 加固的同时应适当衡量历史建筑的历史价值与 建筑的保护后再利用目的这两者的大小, 再结合具体的工 程实际情况，根据历史建筑保护原则和特点做出相关的选 择, 而不能盲目的选择某一种加固方案。

（4）对采用增大截面加固法的上海历史建筑抗震加 固的案例分析, 增大截面法可以有效的改善历史建筑的层 间位移角, 轴压比, 截面尺寸以及截面配筋。

（5）钢筋混凝土历史建筑经过抗震加固后，不仅恢 复和保存了建筑的历史风貌, 其历史建筑的使用功能也得 到了明显提升, 保持了历史建筑“修旧如旧”的保护性修缮 原则, 同时历史建筑本身的抗震性能得到提高, 满足规范 规定的安全使用条件, 实现了优秀历史建筑可持续发展的 目的。

\section{参考文献}

[1] 王永维, 罗苓隆, 吴体, 肖承波, 凌程建. 优秀历史建筑 保护的基本原则 $[\mathrm{J}]$. 四川建筑科学研究, 2010,36(3):1-4。

[2] 杨向荣. 历史建筑修缮过程中的“原真性”保护问题浅议 ——杭州 “富义仓” 修缮为例 [J]. 安徽农学通报, 2007,13(21):41-43。

[3] 张婷. 历史建筑保护原则和改造方法浅析 [J]. 建筑工程技 术与设计, 2014,(16)。

[4] 中华人民共和国住房与城乡建设部. 建筑抗震加固技术规 程[M]. 北京：中国建筑工业出版社，2009:29-31。

[5]四川省住房和城乡建设厅. 混凝土结构加固设计规范 [M]. 北京：中国建筑工业出版社, 2013:21-133。

[6] 于金涛. 混凝土框架结构加固技术综述 [J]. 价值工程, 2017,(11):113-114。

[7] 吴雯. 钢筋混凝土框架结构加固技术的研究与应用 [D]. 西 安：西安工业大学, 2014:28-29。 
[8] 吴成龙, 刘香. 钢筋混凝土框架结构抗震加固方法浅述 [J]. 福建建筑, 2014,(02):9-11。

[9] 住房和城乡建设部防灾究中心. 保护性历史建筑抗震鉴定 加固案例----钢筋混凝土结构册 [M]. 中国建筑工业出版社, 2012: 3-229。
[10] 范夕森, 徐红云, 任淑贞, 吕伟. 历史建筑的隔震加固技 术研究 [J]. 山东建筑大学学报, 2010,(03):255-258。 